\title{
VOX ET FACIES PARA O RETRATO
}

\author{
Vox et facies for the portrait
}

Rodrigo de Almeida Cruz ${ }^{1}$

1e.rodrigocruz@gmail.com 
Como poderíamos situar o retrato diante das noções de voz e de face, de fala e de rosto? No centro dessa questão se desenrola este ensaio visual, fruto das reflexões experimentadas na série os dias, conjunto de trabalhos iniciados em 2017 como parte da minha pesquisa teórica e prática no terreno da pintura. Nela, rostos e vozes, compõem uma tentativa de compreender o funcionamento do retrato no seio da problemática entre a palavra e a imagem.

Tão antigo quanto o nascimento da pintura, presente em mais de um dos seus mitos, o retrato tem uma história associada tanto à luta contra a indistinção da morte, à sobrevivência à assimilação do tempo, à expressão verdadeira de uma subjetividade, quanto à confirmação de uma ausência, ao desaparecimento do outro, à substituição própria do re-presentar. Um breve olhar sobre a origem da palavra revela rapidamente os termos da aporia que funda o retrato. Proveniente do italiano ritratto (HOUAISS, 2009, p. 1660), ela está ligada ao vocábulo latino retrahere, retirar, desviar, recusar, subtrair, mas também, restabelecer, fazer reviver, fazer vir, trazer por força. Como "retrahere ab interitu", "salvar da morte", ou, "retrahere verba coram amico", "calar-se na presença de um amigo" (SARAIVA, 2000, p. 1036).

A despeito da necessidade de que o modelo esteja ou não calado no momento do retratar, a fala, assim como a voz, não costumam ser associadas à ideia do retrato, muito embora possuam como traço comum a noção da singularidade. Algo nesse sentido é assinalado por Walter Benjamin quando aponta para o caráter manual, artesanal, do trabalho do narrador, daquele que conta histórias oralmente, que "imprime na narrativa" sua marca, "como a mão do oleiro na argila do vaso" (1994, p. 225). De modo semelhante, Benjamin vai situar o retrato, o "rosto humano", como a "última trincheira", estabelecida no surgimento da fotografia, contra a "existência serial" da obra de arte (1994, p. 168-174).

Essa trincheira é, no entanto, desafiada pelo trabalho de artistas como Zanele Muholi, Taryn Simon, Walid Raad e Christian Boltanski, "que tomam as coleções, arquivos e séries de fotos similares (pessoais ou alheios) como veículos para refletir sobre como as imagens funcionam sozinhas e coletivamente" (LAW-VILJOEN, 2016, p. 27). A preocupação de Benjamin com a "autenticidade", com a "existência única da obra de arte", o que ele também definiu como sua "aura", intimamente ligada ao valor de culto, ao passado mágico e ritual das obras de arte (p. 173), encontra no trabalho de tais artistas uma dimensão irresoluta. Muholi, por exemplo, em Faces e Fases (2006-2014) usa a serialidade e a repetição para construir uma espécie de memento mori como resposta à natureza serial dos crimes contra pessoas LGBTI na África do Sul (LAW-VILJOEN, 2016, p. 27-29). Já Boltanski (em trabalhos como Archives, 1988, 364 Suisses mort, 1990, dentre outros) utiliza retratos documentais de arquivos públicos para construir monumentais reflexões sobre a banalidade da vida ou de um rosto humano em meio a milhares de rostos. Poderíamos certamente acrescentar a esse grupo o pintor alemão Gerhard Richter, não só pelo seu famoso Atlas, mas também pelo trabalho 48 Retratos (1971-72), que toma como referência fotografias publicadas em enciclopédias, com o objetivo de abalar a tradição que compreende o retrato como a expressão viva de uma personalidade, e que teve seu ápice na construção de uma identidade burguesa no século XIX. Vale mencionar que é exatamente nessa problemática que se inserem os trabalhos da série os dias. Neles 
são utilizadas estratégias semelhantes àquelas empregadas vastamente por Richter, tais como a cópia, por meio da pintura a óleo, de fotografias (em busca de negar um pensamento compositivo próprio da pintura); o uso do preto e branco atrelado ao caráter documental; o impacto cumulativo da repetição e da serialidade ${ }^{1}$. Todas estratégias acionadas com o objetivo de negar o caráter subjetivo do retrato, sua suposta expressão de um em-si do sujeito.

O filósofo francês Jean Luc Nancy, desconfiando da existência desse em-si do sujeito, que se revelaria no retrato, afirma que o que vemos é então o próprio mistério da alteridade, pois no retrato o outro se retira se mostrando: "ll est retiré dans son altérité" (NANCY, 2014, p. 18). Nancy coloca essa mesma questão no âmbito da fala, no texto Vox Clamans in deserto, um ensaio cujo próprio formato sugere que "para falar da voz [...] é preciso ouvir as diferentes vozes" (LYRA, 2016, p. 140). Numa espécie de encenação, que remete ao teatro grego, o texto é composto por um diálogo no qual, vez por outra, autores como Roland Barthes, Hegel, Jacques Derrida, dentre outros, são chamados a falar, e, com o auxílio de máscaras, entram, por assim dizer, em cena. Enquanto um dos interlocutores, "colocando uma máscara que se assemelha a Roland Barthes", afirma que "A voz humana é, de fato, o lugar privilegiado (eidético) da diferença" (2012, p. 11), vai se revelando uma estranha imbricação: para falar com a voz de Barthes, o narrador de Nancy precisa vestir-se com sua efígie, e, de fato, retirar-se de si. A voz e o rosto caminham juntos para produzir, ambiguamente, o mesmo e o outro.

Algo semelhante acontece na série os dias: de caráter colaborativo, a série depende dos depoimentos cedidos pelas pessoas retratadas, depoimentos que possuem como elemento comum o fato de versarem sobre um dia qualquer. Esses depoimentos são gravados a laser em uma placa de madeira compensada e, assim, apresentados junto às pinturas. Em outros termos, cada sujeito, escolhido de modo arbitrário, precisa narrar um dia da sua vida para constituir seu retrato, de modo que cada face, compreende também o lugar de uma voz, e, assim, juntas, a face e a voz assumem o lugar do sujeito, retirado que está em sua alteridade.

\footnotetext{
1 Segundo o pintor alemão Gerhard Richter, no grupo de trabalhos 48 retratos (48 Portraits, 1972) seu critério para seleção das fotografias que seriam pintadas, tomadas de enciclopédias, fora o caráter objetivo, despido de um estilo artístico ("objective photographs with no artistic style of their own", 2009, p. 63). Sabemos que a noção de "artístico" negada por Richter desde que em 1962 ele começou a fazer suas pinturas baseadas em fotos, corresponde a uma prática fotográfica deliberadamente elaborada, oposta ao caráter documental, e frequentemente banal, encontrado por ele nos álbuns de família, nas fotografias amadoras e nas enciclopédias. Ao partir desse ponto de vista para fazer seus retratos, o pintor alemão golpeia duplamente a tradição da pintura. Primeiro, desestabiliza a ideia de retrato remanescente da tradição pictórica que se estabeleceu no século 19, com suas noções de identidade burguesa e de subjetividade. Segundo, define como método de trabalho uma escolha negativa, isto é, de negação dos problemas característicos da pintura, bem exemplificada pela seguinte declaração: "Quando desenho - um homem, um objeto - tenho que estar consciente da proporção, exatidão, abstração ou distorção, e assim por diante. Quando faço uma pintura a partir de uma foto, o pensamento consciente é interrompido. Não sei o que faço. Meu trabalho fica muito mais próximo do informal do que de qualquer tipo de 'realismo'. A foto tem uma abstração própria, que não é tão fácil assim de ser descoberta" (2006, p. 113). Foi pensando na estratégia de Richter que se dera minha escolha de composição dos retratos (documental e burocrática) assim como a opção por pintar as fotografias feitas para a série os dias, isto é, para afirmar, desafiando a pintura, certo caráter objetivo, e assim mergulhá-la na dimensão serial, de coleções, enciclopédias e arquivos.
} 


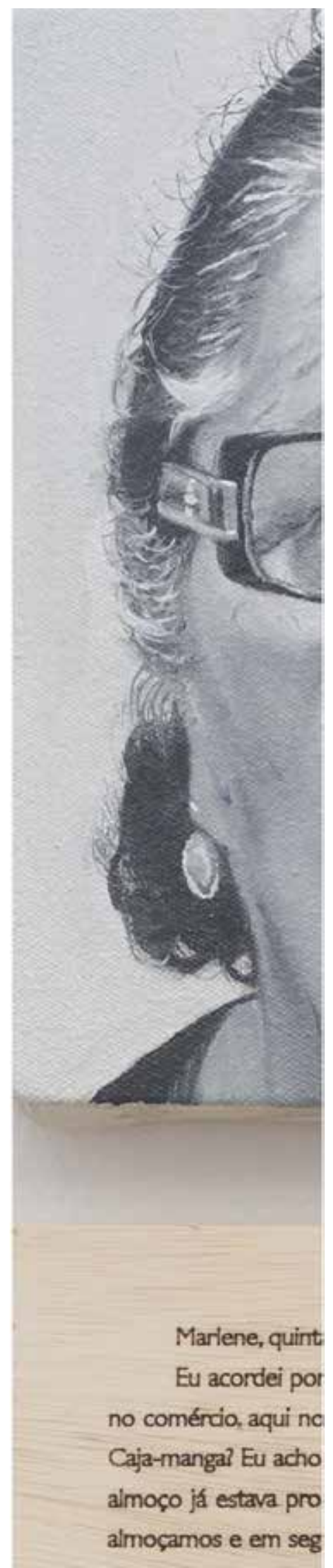

Detalhe do trabalho Marlene da série os dias. Óleo sobre tela e gravação a laser em placa de madeira compensada. Cerca de $50 \mathrm{~cm} \times 21 \mathrm{~cm}$. 2017. (Foto: Jean Peixoto). 


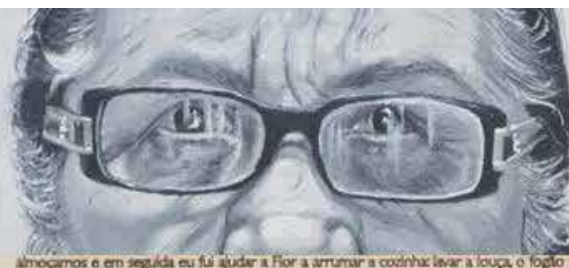
20

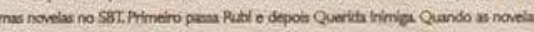

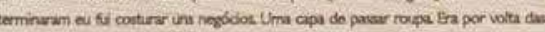

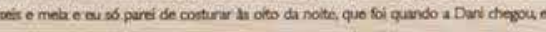

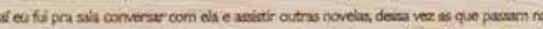

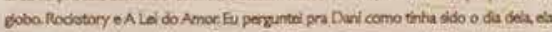

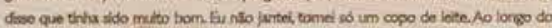

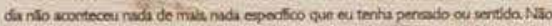

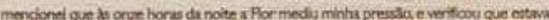

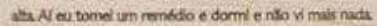

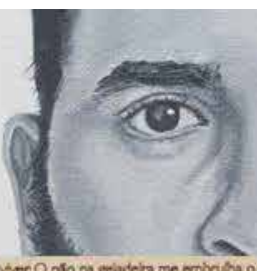
her 0 plo na gelade

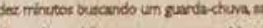
DreA moctilis pera com o nocustrio ph Paro na pidaria no conthho pars

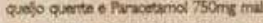

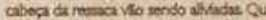

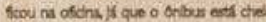

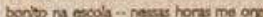

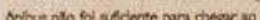
che

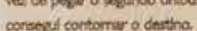

dregando ne eccois, thes mintos

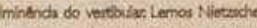

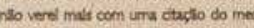

Colagem feita com detalhes dos trabalhos Leonardo, Marlene e Gabriel da série os dias. Óleo sobre tela e gravação a laser em placa de madeira compensada. Cerca de $50 \mathrm{~cm}$ x $21 \mathrm{~cm}$ (cada). 2017 .

(Foto: Jean Peixoto). 


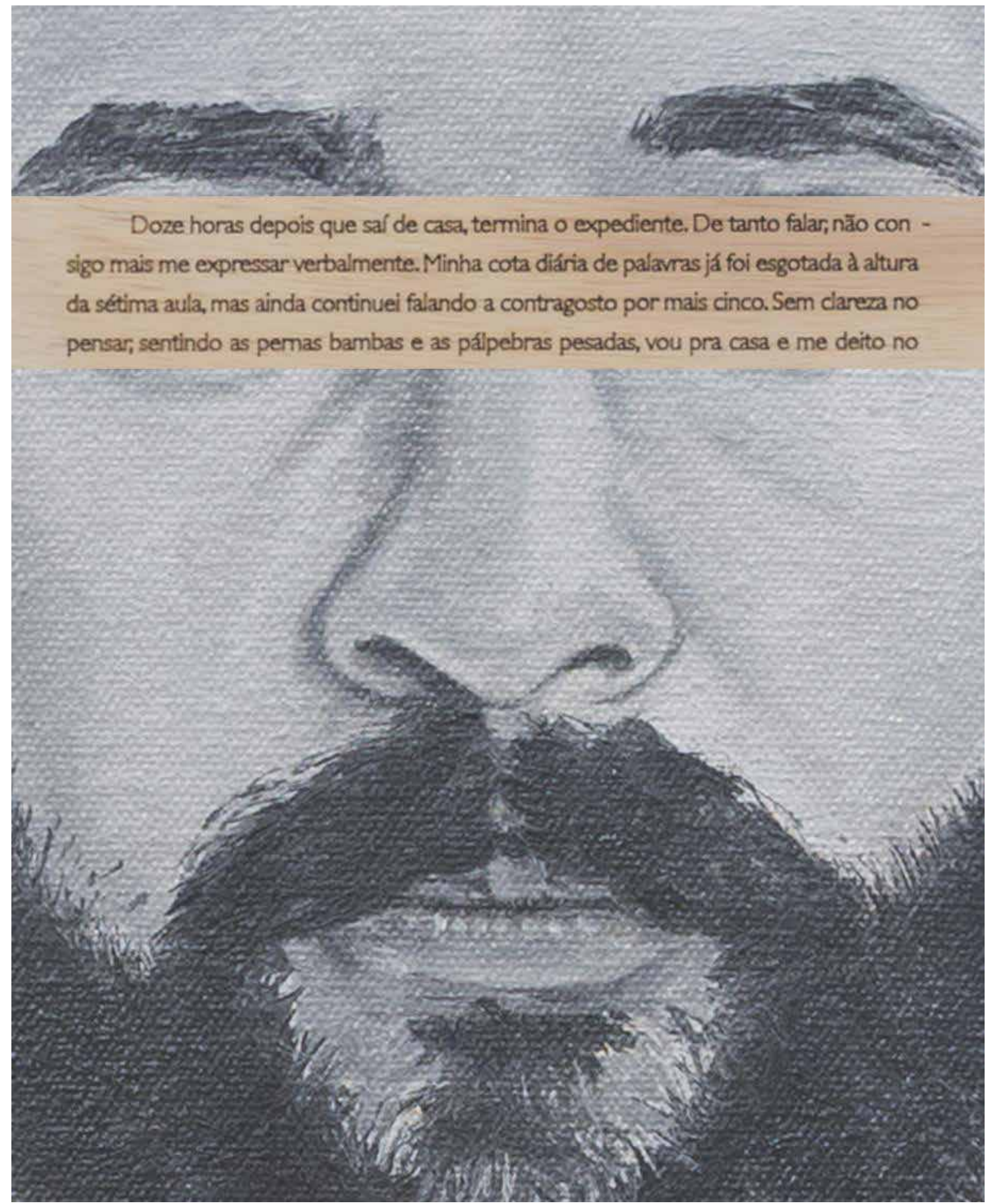

Colagem feita com detalhes do trabalho Gabriel da série os dias.

Óleo sobre tela e gravação a laser em placa de madeira compensada. Cerca de $50 \mathrm{~cm}$ x $21 \mathrm{~cm} .2017$. (Foto: Jean Peixoto). 


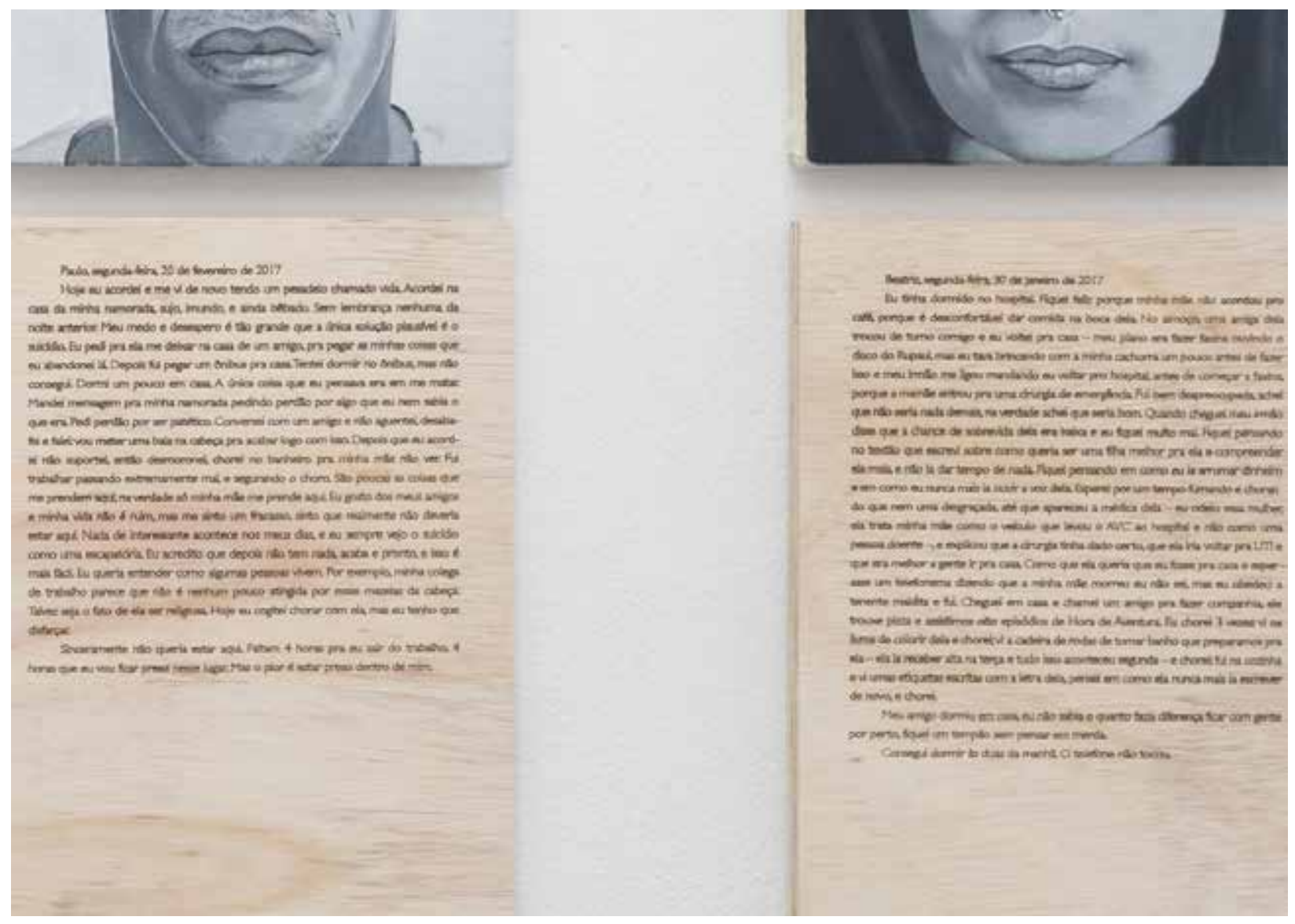

Detalhe dos trabalhos Paulo e Beatriz da série os dias. Óleo sobre tela e gravação a laser em placa de madeira compensada. Cerca de $50 \mathrm{~cm}$ x $21 \mathrm{~cm}$ (cada). 2017. (Foto: Jean Peixoto). 

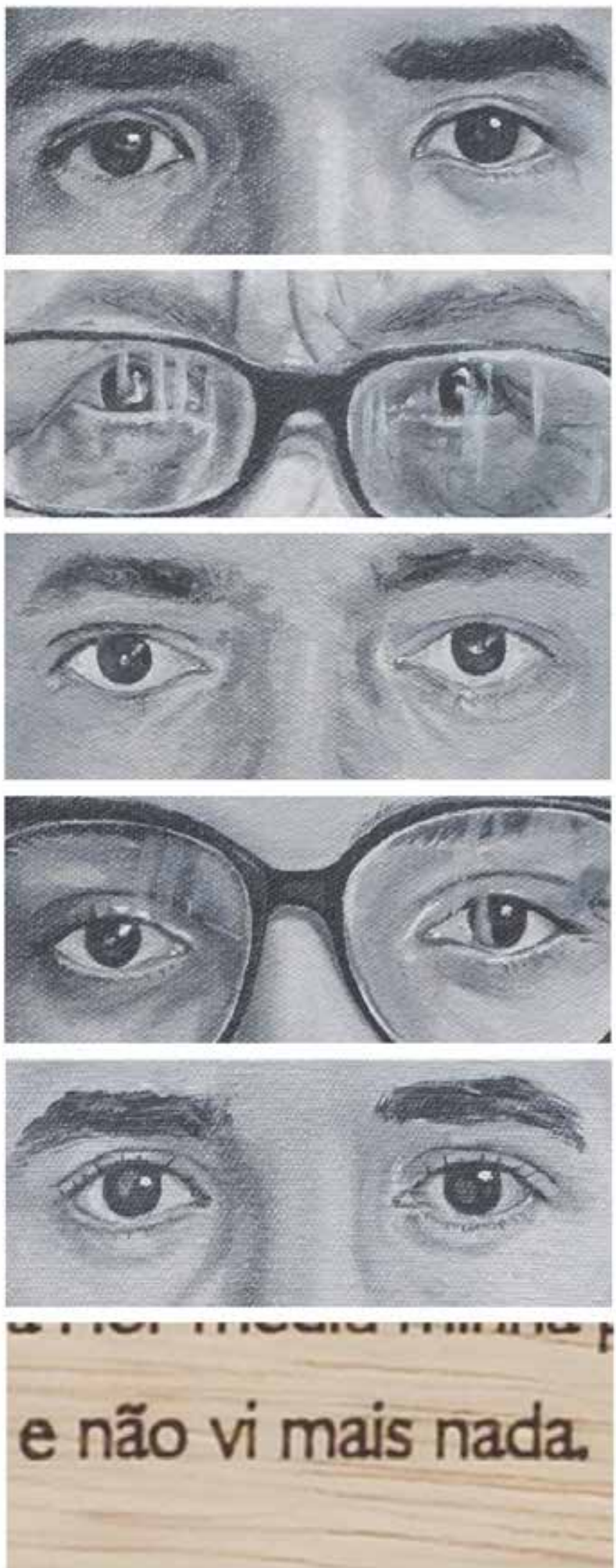

Colagem feita com detalhes dos trabalhos Paulo, Marlene, Leonardo, Beatriz e Gabriel da série os dias. Óleo sobre tela e gravação a laser em placa de madeira compensada. Cerca de $50 \mathrm{~cm} \times 21 \mathrm{~cm}$ (cada). 2017. (Foto: Jean Peixoto). 


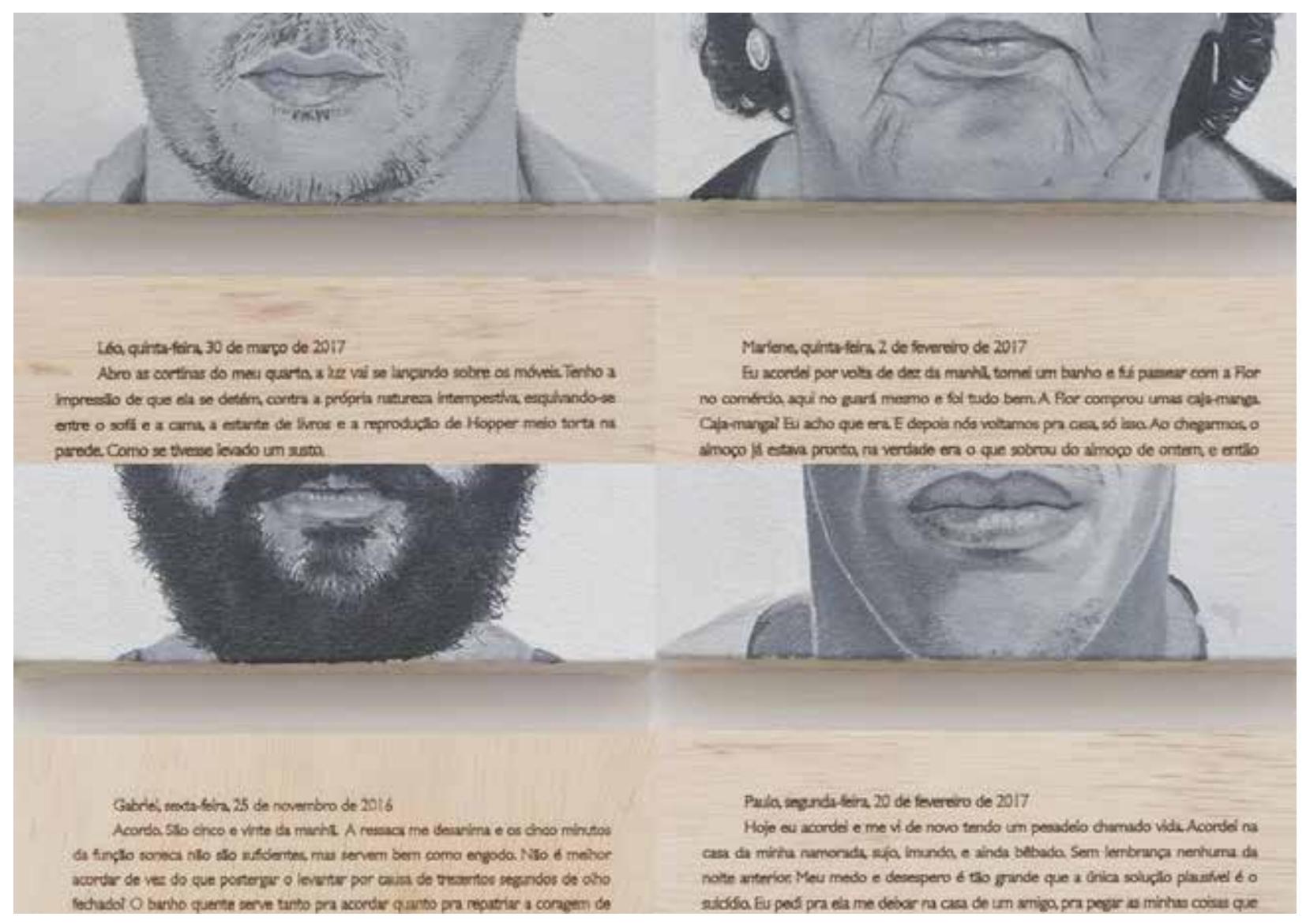

Detalhes dos trabalhos Leonardo, Marlene, Gabriel e Paulo da série os dias.

Óleo sobre tela e gravação a laser em placa de madeira compensada. Cerca de $50 \mathrm{~cm}$ x $21 \mathrm{~cm}$ (cada). 2017. (Foto: Jean Peixoto). 


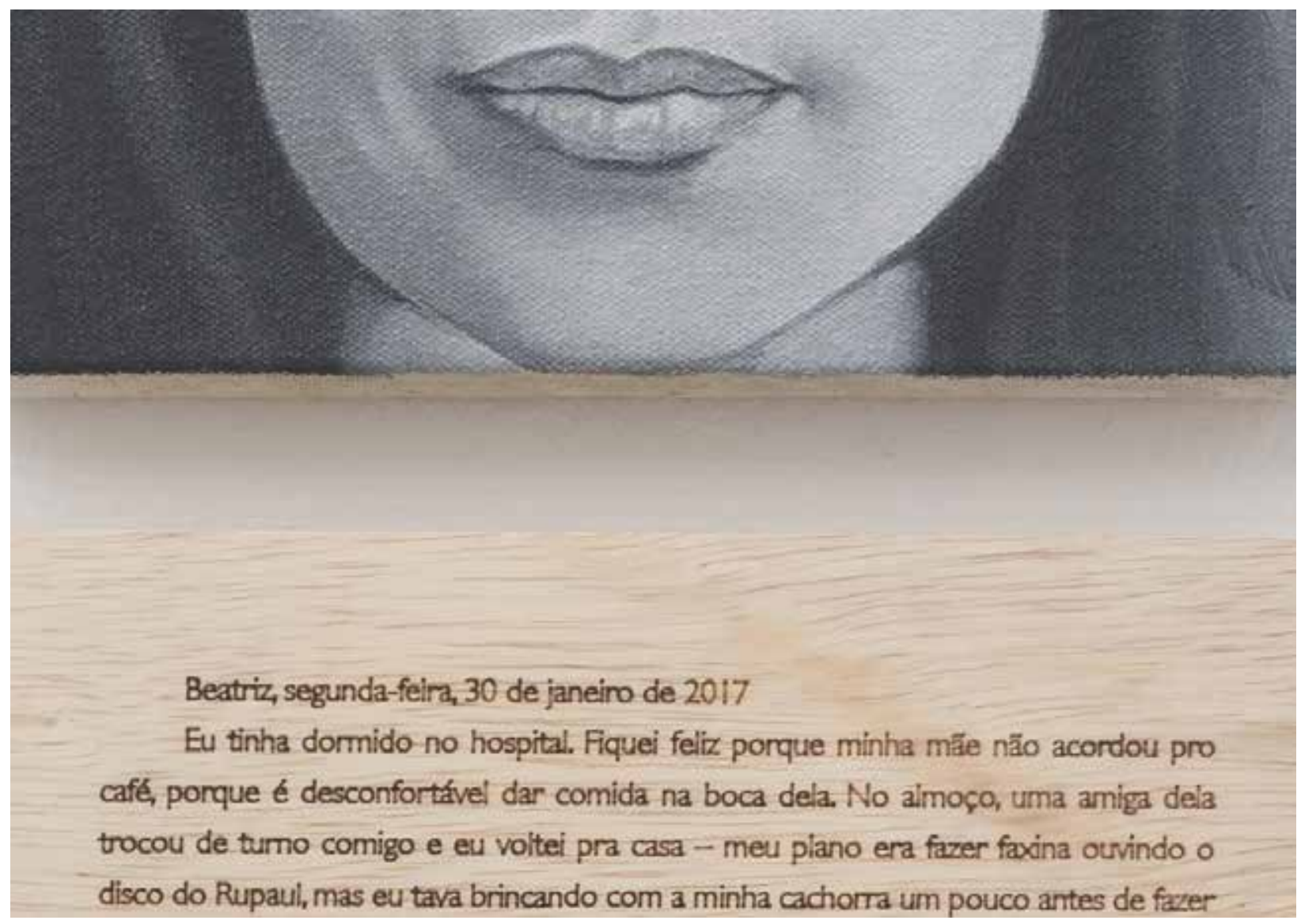

Detalhe do trabalho Beatriz da série os dias. Óleo sobre tela e gravação a laser em placa de madeira compensada. Cerca de $50 \mathrm{~cm} \times 21 \mathrm{~cm}$. 2017. (Foto: Jean Peixoto). 


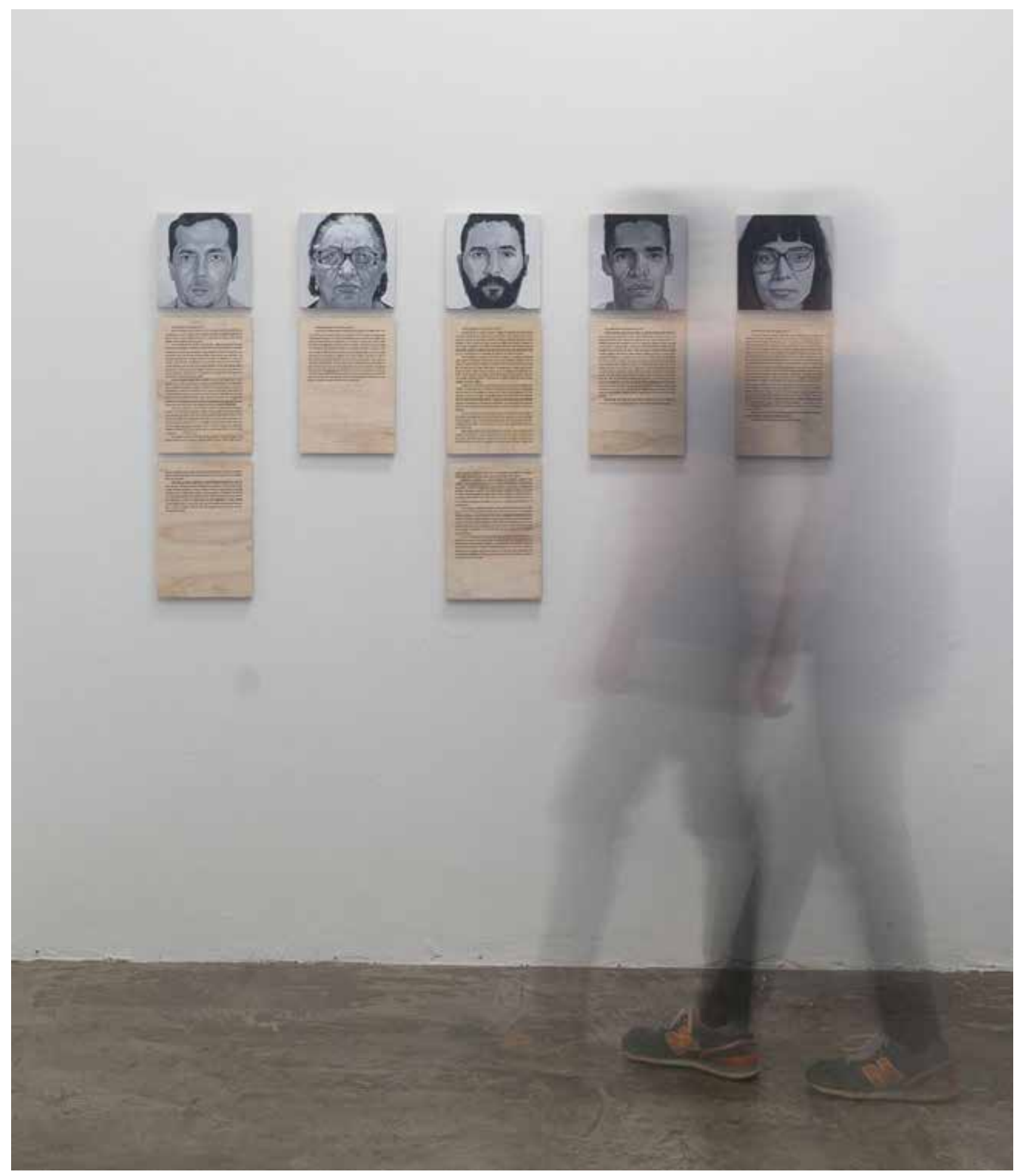

Vista frontal dos trabalhos da série os dias. (Foto: Jean Peixoto). 


\section{Referências}

BENJAMIN, Walter. Magia e técnica, arte e política: ensaios sobre literatura e história da cultura. - 7 ed. - São Paulo: Brasiliense, 1994.

HOUAISS, Antônio. Dicionário Houaiss da língua portuguesa. Rio de janeiro: Objetiva, 2009.

LAW-VILJOEN, Bronwyn. Uma por todas. In: Zum: Revista de Fotografia, ed. 11. São Paulo: Instituto Moreira Salles, 2016.

LIRA, Clarisse. Los detectives salvajes, sua promessa de sentido. In: Toda orfandade do mundo: escritos sobre Roberto Bolaño. Org. Antonio Marcos Pereira, Gustavo Silveira Ribeiro. - Belo Horizonte: Relicário Edições, 2016)

NANCY, Jean-Luc. L'Autre Portrait. Paris: Galilée, 2014.

Vox Clamans in Deserto. In: Gratuita : volume 2 / Organizadora Maria Carolina Fenati - Belo Horizonte: Chão da Feira, 2015. Disponível em: http://chaodafeira.com/wp-content/uploads/2015/06/Gratuita-vol.-2-Caderno-de-Leituras. pdf. Acesso: 23/03/2018.

RICHTER, Gerhard. Writings 1961-2007. New York: d.a.p, 2009.

Notas, 1964-1965. In: Escritos de artistas, anos 60/70. Organização de Glória Ferreira e Cecilia Cotrim. Rio de Janeiro: Jorge Zahar, 2006.

SARAIVA, F. R. dos Santos. Novíssimo Dicionário Latino-Português. Rio de janeiro: Garnier, 2000. 